\title{
High etch-resistant EB resists employing adamantyl protective groups and their application for 248-nm lithography
}

\author{
Koji Nozaki, Jun-ichi Kon, and Ei Yano \\ Fujitsu Laboratories Ltd. \\ 10-1 Morinosato-Wakamiya, Atsugi 243-0197, Japan \\ E-mail:knozaki@flab.fujitsu.co.jp
}

\begin{abstract}
We developed high-etch resistant resists for electron beam (EB) lithography. The incorporation of 2-alkyl-2-adamantyl groups as cleavable protective groups in a vinylphenolmethacrylate copolymer enabled us to enhance the dry-etch resistance and obtain excellent lithographic performance. In this paper, we investigate the reactivity of 2-methyl(MAd) and 2-ethyladamantyl (EAd) group for an acidic condition as well as the heatflow resistance of the resist. In addition, we applied vinylphenol-2-ethyl-2-adamantyl methacrylate (VP-EAdMA)-based resist to 248-nm exposures. We found that the reactivity of the EAd group was 2.5 times higher than that of the MAd group. We also found that the resist had a $140-\mathrm{nm}$ resolution at $13.2 \mathrm{~mJ} / \mathrm{cm}^{2}$ without optimization of the process conditions. We think that these resists can be used for both EB and 248-nm exposure systems.
\end{abstract}

Keywords: EB resist, adamantyl groups, 248-nm lithography, alicyclic methacrylate

\section{Introduction}

For the next generation lithography, whose target dimensions less than $100 \mathrm{~nm}$, electron beam (EB) lithography is considered as a promising technique. EB lithography does not require consideration of the absorbance of a resist materials because an EB has very short wavelength $(\lambda=$ $3.7 \mathrm{pm}$ for $100 \mathrm{keV}$ ). Therefore, there are few limitations on the composition of the EB resist. Electron beam projection lithography (EPL), which uses high-speed EB exposure systems such as SCALPEL [1], PREVAIL [2], and BAA [3], can overcome the low throughput problem in a conventional EB direct-write lithography. To incorporate high-speed EB exposure systems into a mass production process, high sensitive EB resists that have a high resolution capability need to be developed.

To improve resolution and sensitivity, chemically amplified systems are currently used in microlithography resists. In these resist systems, pro- tective groups for acidic functional groups play an important role. A variety of protective groups (i.e., acetals [4], tert-butoxycarbonyl [5], tert-butyl [6], etc.) are used in polyvinylphenol (PVP)based resists. These protective groups, however, have poor dry-etching resistance, which derives from their aliphatic structures. The use of such protective groups usually deteriorates the etch resistance of the resists. On the other hand, there are etch-resistant protective groups having alicyclic structures, such as adamantyl [7], isobornyl [8], and tricyclodecanyl [9] which have been developed for $193-\mathrm{nm}$ resists. This characteristic helps create high etch-resistant resists, which can reduce the resist film thickness and thus improve resolution and sensitivity.

We have already reported on the use of acid cleavable adamantyl groups in PVP-based resists. [10] Since the adamantyl groups have a high etch resistance, strong hydrophobicity, and high reactivity, we think that the incorporation of such 
groups in PVP resists is necessary to use for EPL. In this paper, we investigate the dissolution inhibition of the protective groups, the reactivity of 2-methyl- (MAd) and 2-ethyladamantyl (EAd) group for an acidic condition, the heat-flow resistance of the resist, and the lithographic performance of EB exposures. We also examined the lithographic capabilities of a poly(VP-EAdMA)based resist for 248-nm exposures.

\section{Experimental}

\subsection{Materials}

The acrylate monomer, tert-butyl acrylate (tBuA) was purchased from Aldrich Co.. The methacrylate monomers, 2-methyl-2-adamantyl methacrylate (MAdMA), and 2-ethyl-2-adamantyl methacrylate (EAdMA) were synthesized according to the patent manuscript.[11] A series of polymers, poly(VP-tBuA), poly(VP-MAdMA), and poly(VP-EAdMA) were synthesized with various monomer feed ratios by using 2,2'-azobis(isobutyronitrile) (AIBN) as the initiator. Figure 1 shows the structural formula of poly(VP-MAdMA) and poly(VP-EAdMA). Triphenylsulfonium triflate (TPSOTf) was purchased from Midori Chemical Co. for use as a photo acid generator (PAG). Propylenglycol 1-monomethylether 2-acetate (PGMEA) was purchased from Tokyo Kasei Co. for use as a casting solvent.

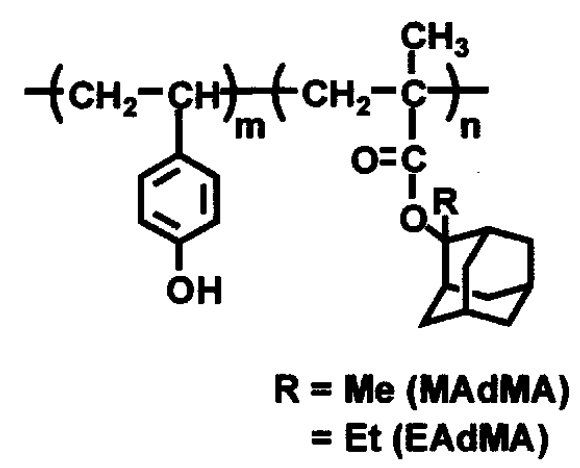

Figure 1. Structural formula of poly(VP-RAdMA).

\subsection{Synthesis}

All polymers were synthesized by free radical solution polymerization. For example, poly $\left(\mathrm{VP}_{79^{-}}\right.$ MAdMA $_{21}$ ) was prepared as follows: a solution of $10 \mathrm{~g}(61.7 \mathrm{mmol})$ of 4-acetoxystyrene (AS),
$5.00 \mathrm{~g}(21.3 \mathrm{mmol})$ of MAdMA, $27.4 \mathrm{~mL}$ of dioxane and magnetic stir bar was stirred under a dry nitrogen atmosphere. To this mixture was added $2.03 \mathrm{~g}(12.3 \mathrm{mmol})$ of AIBN and stirred at $70^{\circ} \mathrm{C}$. After 7 hours, the mixture was precipitated in 1.5 $L$ of methanol, filtered off with a glass filter, and dried in vacuo at $45^{\circ} \mathrm{C}$ for 6 hours. The resultant white powder was dissolved in THF and then reprecipitated in $1.5 \mathrm{~L}$ of methanol, filtered off using a glass filter, and dried again. This reprecipitation procedure was repeated one more time to provide poly(AS-MAdMA) as a white powder. According to the literature [12], deacetylation reaction was performed, which yielded $7.84 \mathrm{~g}$ of the copolymer $(\mathrm{Mw}=7,900, \mathrm{Mw} / \mathrm{Mn}=1.35)$.

\subsection{Analytical measurements}

A JEOL GX500 spectrometer operated at a resonance frequency of $500 \mathrm{MHz}$ for protons was used to obtain the NMR spectra. The IR spectra were measured by a JEOL JIR-100 spectrometer. The molecular weights determination were performed with a TOSOH SC-8020 chromatograph. The molecular weights are linear polystyrene standard (TOSOH)-equivalent.

\subsection{Analysis of deprotection of protective groups}

'H-NMR spectroscopy was used to analyze acidic deprotection of the protective groups. Deuterium chloride ( $\mathrm{DCl}, 20 \mathrm{wt} \%$ solution in $\mathrm{D}_{2} \mathrm{O}$, Aldrich Co.) was used as the acid catalyst. Each monomer $\left(4.31 * 10^{-5} \mathrm{~mol}\right)$ was dissolved in $0.7 \mathrm{~mL}$ of DMSO- $d_{6}$ with $36 \mathrm{mg}$ of the $\mathrm{DCl}$ solution. A reference ' $\mathrm{H}-\mathrm{NMR}$ spectra was obtained with these samples. Next, each sample was heated to $120^{\circ} \mathrm{C}$ for 180 seconds in an oil bath. After reaction, the ${ }^{1} \mathrm{H}$-NMR spectra were measured. The ${ }^{1} \mathrm{H}$ NMR spectra of each sample before and after heating were then compared. 2.5 Resist formulation and lithographic evalua-
tion

Each resist consisted of copolymer, $5 \mathrm{wt} \%$ of TPSOTf, and PGMEA. The well-mixed resist solution was then filtered through a series of 0.5 and $0.2-\mu \mathrm{m}$ Teflon membrane filters and spun onto HMDS-primed Si substrates. For the EB exposures, softbaking at $110^{\circ} \mathrm{C}$ for 120 seconds on a hot plate was done to form $0.5-\mu \mathrm{m}$ (for $\mathrm{L} / \mathrm{S}$ pat- 
terns) or $\mathbf{0 . 8 -} \mu \mathrm{m}$ (for hole patterns)-thick films. For the 248-nm exposures, softbaking at $130^{\circ} \mathrm{C}$ for 60 seconds on a hot plate was performed to form $0.4-\mu \mathrm{m}$-thick films. The resist-coated substrates were exposed in an EB exposure system with an acceleration voltage of $50 \mathrm{keV}$, followed by a postexposure bake (PEB) for 120 seconds on a hot plate. Exposures at $248 \mathrm{~nm}$ were conducted using $1 / 2$ annular illumination, and postexposure baking was performed at $110^{\circ} \mathrm{C}$ for 60 seconds. The films were developed in a $2.38 \% \mathrm{TMAH}$ aqueous solution and rinsed in deionized water. The alkali dissolution rate (ADR) was measured in a $4 \%$ TMAH solution.

\section{Results and Discussion}

\subsection{Dissolution inhibition}

We measured the ADR of poly $\left(\mathrm{VP}_{50}-\mathrm{tBuA}_{50}\right)$, poly $\left(\mathrm{VP}_{79}-\mathrm{MAdMA}_{21}\right)$, and poly $\left(\mathrm{VP}_{79}-\mathrm{EAdMA}_{21}\right)$ in a $4 \%$ TMAH solution. In the case of poly $\left(\mathrm{VP}_{50^{-}}\right.$ $\mathrm{tBuA}_{50}$ ), the ADR decreased from $10^{5} \AA / \mathrm{s}$ (PVP) to $4.7 \AA / \mathrm{s}$ when $50 \mathrm{~mol} \% \mathrm{tBu}$ group was incorporated into the polymer. On the other hand, in the case of MAd and EAd containing polymers, it was possible to reduce the ADRs to $5.9 \AA / \mathrm{s}$ and $2.0 \AA / \mathrm{s}$ respectively when $21 \mathrm{~mol} \%$ of the adamantyl groups was incorporated (Figure 2). This result indicates that the adamantyl groups have stronger dissolution inhibition than that of the $\mathrm{tBu}$ group. We think that the highly hydrophobic nature and the bulky structure of the adamantyl groups causes such strong dissolution inhibition.

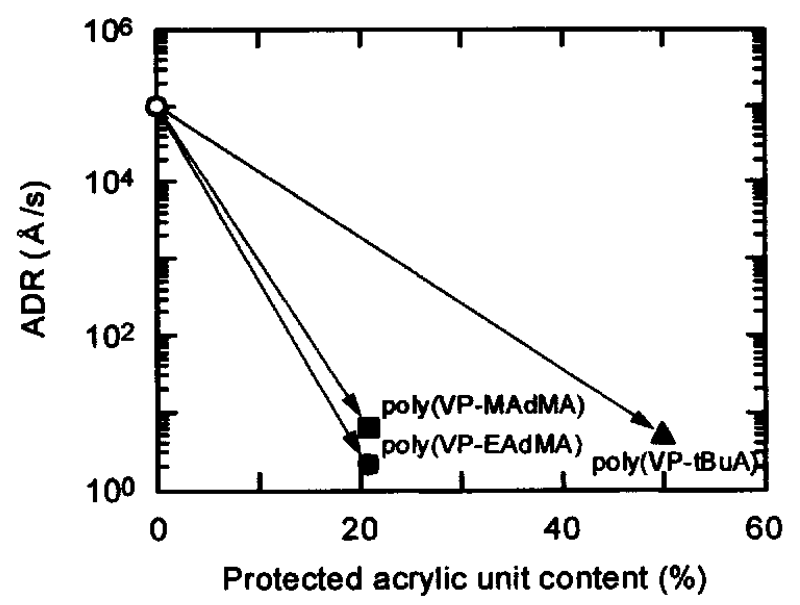

Figure 2. Dissolution rate chages of VP-protected (meth)acrylate copolymers in a 4.0\% TMAH solution.
When we apply such protective groups into a resist, we can obtain a large polarity change with a small amount of deprotection of such protective groups. We believe that the polarity change gives a high sensitivity and a high contrast.

\subsection{Deprotection of protective groups}

Figure 3 illustrates the change in the NMR spectra of MAdMA. Before the acid cleavage reaction, the singlet peak for the protons $(2 \mathrm{H})$ on the bridgehead position at $\delta=2.27 \mathrm{ppm}$ was observed. After the reaction, a new singlet peak at $\delta=2.46 \mathrm{ppm}$ appeared in the spectrum, which we assigned to the bridgehead protons of the vinyl product (2-methyleneadamantane). The ratio of integral values between 2-methyleneadamantane and unchanged MAdMA was 0.12 to 0.38 , and hence, the deprotection conversion was calculated at $24 \%$.

Figure 4 shows the change in the NMR spectra of EAdMA. The peak for the methyl protons $(3 \mathrm{H})$ in the ethyl group was observed at $\delta=0.73$ ppm before the acid cleavage reaction. A doublet peak at $\delta=1.51 \mathrm{ppm}$ resulted from the reaction, which was assigned to the methyl protons $(\mathrm{C}=\mathrm{CH}$ $\mathrm{CH}_{3}$ ) of the deprotected product (2-ethenyladamantane). The integral values for 2-ethenyladamantane and unreacted EAdMA were 0.46 and 0.29 , respectively. Thus, the calculated deprotection conversion was $61 \%$.

As a reference, we also analyzed tert-butyl methacrylate (tBuMA) in the same manner (Figure 5). We focused on the peak for the vinyl protons because the $\mathrm{tBu}$ group changes into gaseous isobutene after the reaction. The integral values for methacrylic acid and unreacted tBuMA were 0.46 and 0.29 , respectively. Thus, the calculated deprotection conversion was $18 \%$.

Table 1 shows the result of the acid deprotection of the protective groups. The relative reactivity to the tBu group was 3.4 for the EAd group, and 1.3 for the MAd group. The EAd group's deprotection conversion was 2.5 times higher than that of the MAd group under this condition. We think that the high reactivity of the EAd group reflects the stability of the intermediate in the deprotection reaction. The MAd group has three protons in methyl group, which enable to stabilize the carbonium ion on the intermediate by hyperconjugation, while the EAd has two protons 


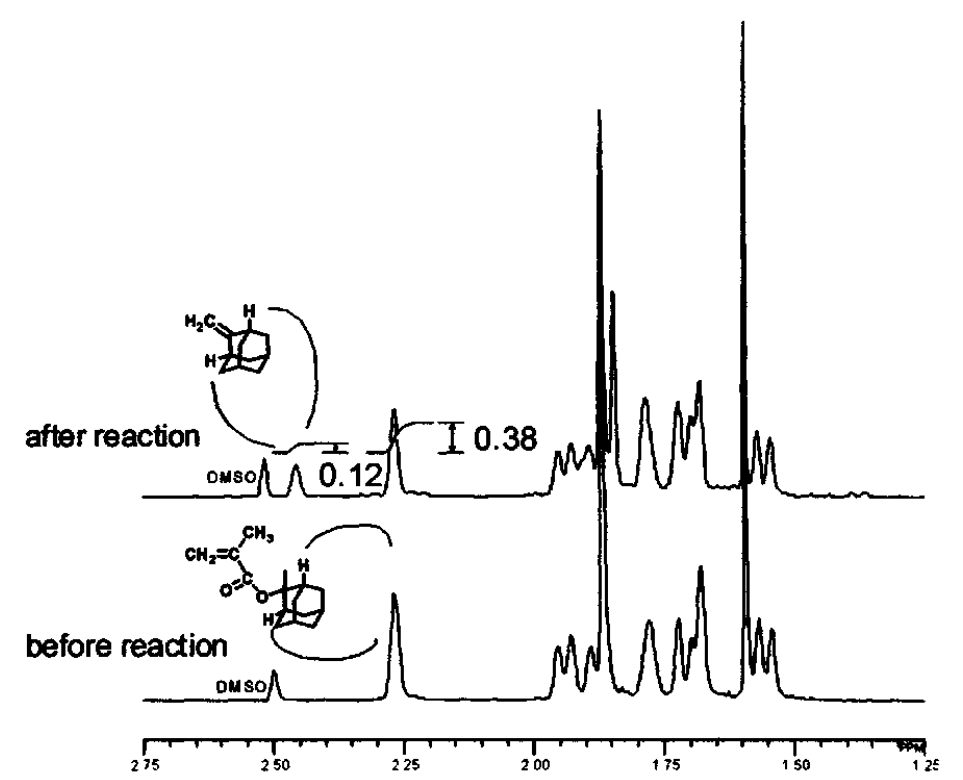

Figure 3. NMR spectra of MAdMA before and after acid cleavage reaction.

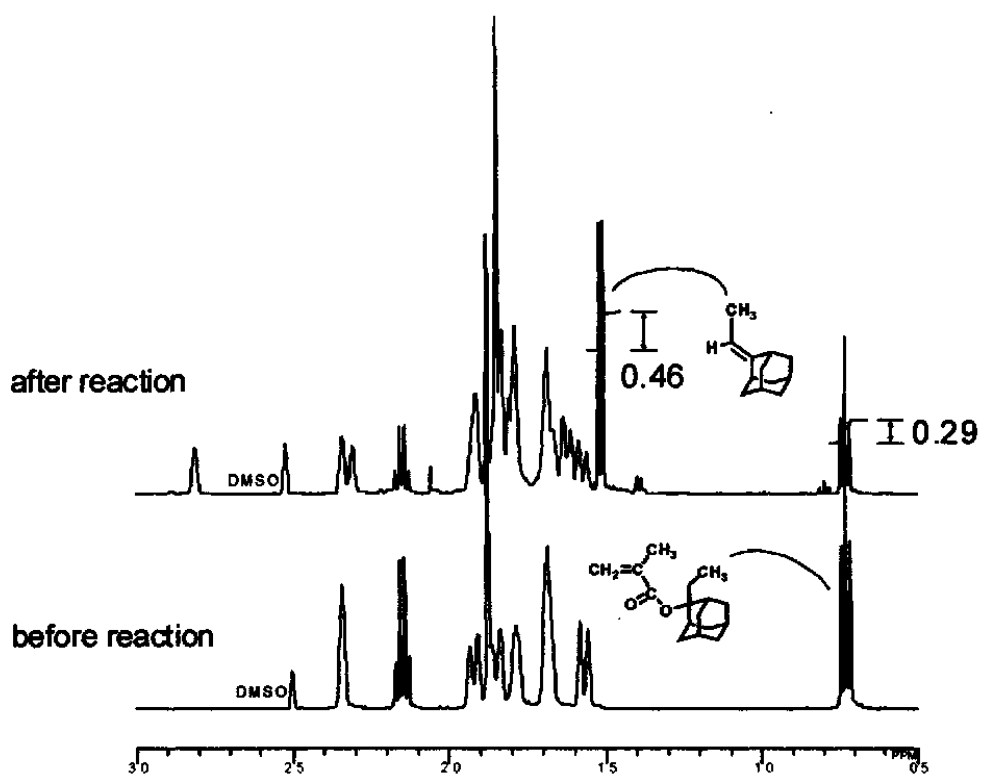

Figure 4. NMR spectra of EAdMA before and after acid cleavage reaction.

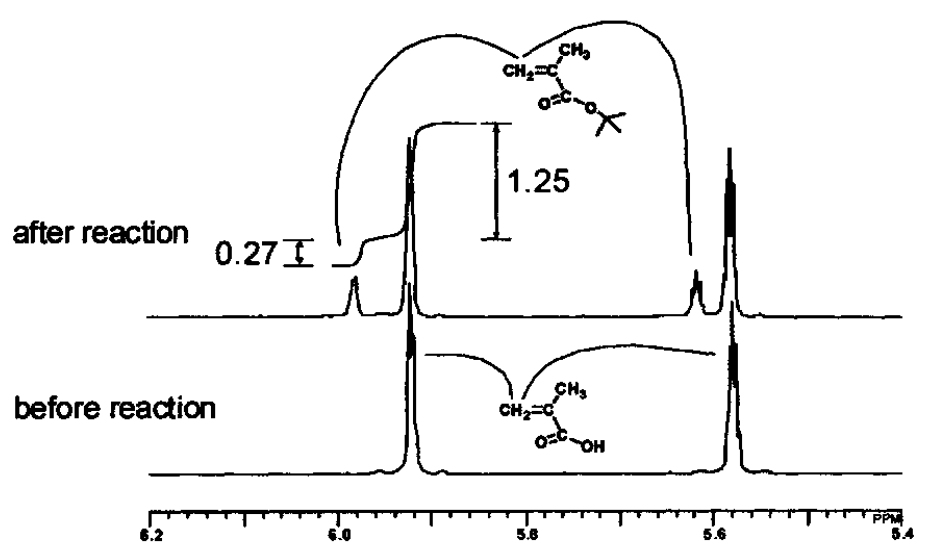

Figure 5. NMR spectra of tBuMA before and after acid cleavage reaction. 
Table 1. Deprotection conversion of the protective groups

\begin{tabular}{ccc}
\hline Starting monomer $(\delta$ in ppm) & product & relative reactivity \\
\hline & & \\
& &
\end{tabular}

and a methyl group in ethyl substituent. The methyl group in the ethyl substituent of the EAd has an inductive effect, which also contributes to stabilization of the carbonium ion on the intermediate. We think that the stabilization capability of the inductive effect of a methyl group was stronger than that of the hyperconjugation of a proton. Therefore, we think that EAd has higher reactivity than that of the MAd. Although the results imply acidic hydrolysis of the protective groups, we think that they explain the acidic reactivity of the protective groups to some extent.

\subsection{Lithographic performance for EB exposures}

Figure 6 shows SEM micrographs of the hole patterns. The poly $\left(\mathrm{VP}_{50}-\mathrm{tBuA}_{50}\right)$-based resist resolved $110 \mathrm{~nm}$ at $9.0 \mu \mathrm{C} / \mathrm{cm}^{2}$, the poly $\left(\mathrm{VP}_{79}-\mathrm{MAd}-\right.$ $\mathrm{MA}_{21}$ )-based resist resolved $104 \mathrm{~nm}$ at $9.0 \mu \mathrm{C} / \mathrm{cm}^{2}$, and the poly $\left(\mathrm{VP}_{79}-\mathrm{EAdMA}_{21}\right)$-based resist resolved $98 \mathrm{~nm}$ at $6.0 \mu \mathrm{C} / \mathrm{cm}^{2}$. The poly $\left(\mathrm{VP}_{79}\right.$-EAd$\mathrm{MA}_{21}$ )-based resist displayed the highest resolution and sensitivity, we think that the result is in accord with the EAd group's high reactivity and strong hydrophobicity. We also used the poly $\left(\mathrm{VP}_{79}-\mathrm{EAdMA}_{21}\right)$-based resist to produce line and space (L/S) patterns. Figure 7 shows the SEM micrographs at a dose of $9.0 \mu \mathrm{C} / \mathrm{cm}^{2}$. The resist resolved $120-\mathrm{nm} \mathrm{L} / \mathrm{S}$ patterns with a $0.5-\mu \mathrm{m}$ thick-
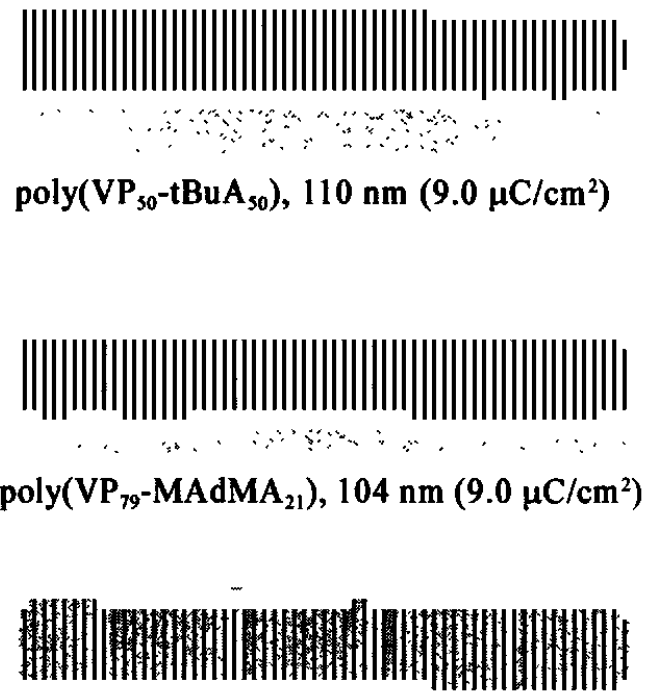

$$
\operatorname{poly}\left(\mathrm{VP}_{79}-\mathrm{EAdMA}_{21}\right), 98 \mathrm{~nm}\left(6.0 \mu \mathrm{C} / \mathrm{cm}^{2}\right)
$$

Figure 6. SEM micrographs of hole patterns obtained by EB exposures $(50 \mathrm{keV})$.

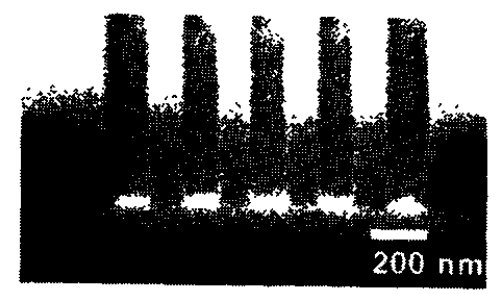

Figure 7. SEM micrographs of $120-\mathrm{nm} \mathrm{L/S}$ patterns obtained by EB exposures ( $50 \mathrm{keV})$. 


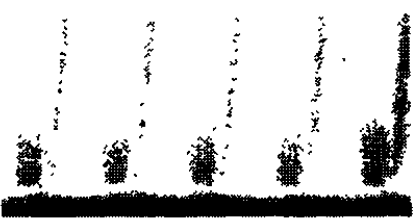

Pattern size $160 \mathrm{~nm}$

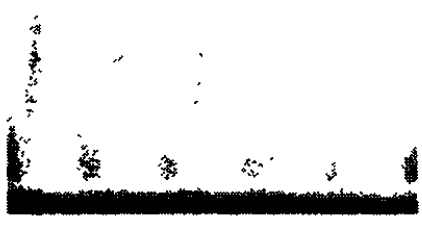

$150 \mathrm{~nm}$

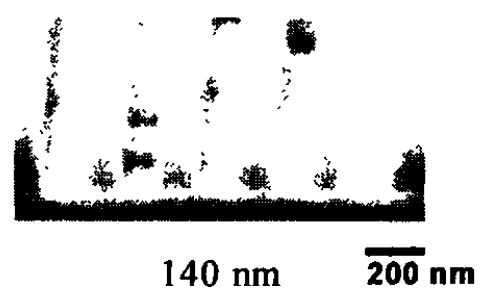

Figure 8. SEM micrographs of $\mathrm{L} / \mathrm{S}$ patterns in $0.4-\mu \mathrm{m}$-thick films exposed with a $\mathrm{KrF}$ stepper $(\mathrm{NA}=\mathbf{0 . 6 8})$ using a base additive containing poly $\left(\mathrm{VP}_{79}-\mathrm{EAdMA}_{21}\right)$-based resist. The exposure dose was $13.2 \mathrm{~mJ} / \mathrm{cm}^{2}$.

ness, which proves the resist can be used for both hole and $\mathrm{L} / \mathrm{S}$ patterns.

\subsection{Lithographic performance for 248-nm expo- sures}

We then applied the poly $\left(\mathrm{VP}_{79}-\mathrm{EAdMA}_{21}\right)$ based resist to 248-nm lithography which displayed the highest resolution for EB exposures. We expect that the resist will be suitable for 248$\mathrm{nm}$ lithography because the transparency of the base resin is high (optical density $=0.15 / \mu \mathrm{m}$ ) at that wavelength. Figure 8 shows its resolution capabilities, exposed with a $\mathrm{KrF}$ stepper (NA $=0.68$ ). Since the clearing dose of the resist was less than $5 \mathrm{~mJ} / \mathrm{cm}^{2}$ (too sensitive), it was difficult to evaluate the lithographic performance. Therefore, we added a base compound to the resist and raised the softbaking temperature to $130^{\circ} \mathrm{C}$ to lower its sensitivity. The resist resolved $140-\mathrm{nm} \mathrm{L/S}$ patterns at a dose of $13.2 \mathrm{~mJ} / \mathrm{cm}^{2}$ without optimization of the process conditions, which suggests that

Table 2. Heat-flow resistance of poly( $\left(V_{79}-E A d-\right.$ $M_{A_{21}}$ )-based resist

Heating time: 5 min

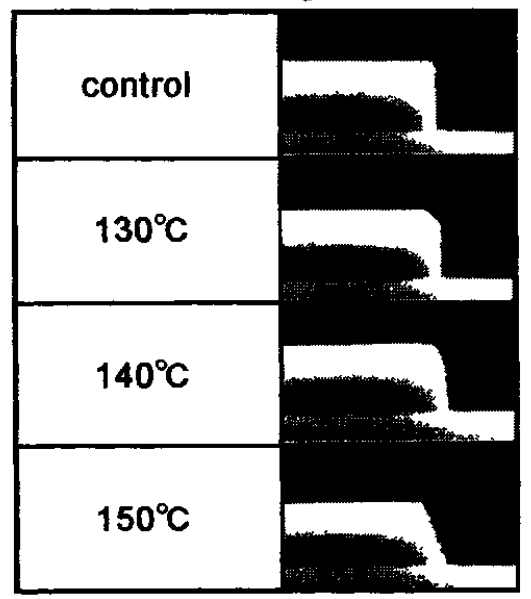

this resist can be suitable to use for both EB and 248-nm lithography.

\subsection{Heat-flow resistance}

We examined the heat-flow resistance of the poly $\left(\mathrm{VP}_{79}\right.$-EAdMA $\left.A_{21}\right)$-based resist. We used 10$\mu \mathrm{m}$ lines printed by a $\mathrm{KrF}$ stepper for this evaluation. After patterning the resist, the resist coated wafers were baked at 130,140 , and $150^{\circ} \mathrm{C}$ for 5 minutes (Table 2). We focused on the edge of the patterns and found there was no pattern deformation up to $130^{\circ} \mathrm{C}$. It is well-known that patterns begin to deform from about $120^{\circ} \mathrm{C}$ in conventional Novolak resists. Thus, we think that our resist has high heat-flow resistance, which is good for semiconductor manufacturing purposes.

\subsection{Dry etching durability}

We investigated the etch rates of poly $\left(\mathrm{VP}_{50^{-}}\right.$ $\left.\mathrm{tBuA}_{50}\right)$, poly $\left(\mathrm{VP}_{56}\right.$-EAdMA $\left.\mathrm{A}_{44}\right)$, poly $\left(\mathrm{VP}_{79}\right.$-EAd$\mathrm{MA}_{21}$ ) and PVP for comparison with Novolak re-

Table 3. Relative dry etching rate of vinylphenolbased resists

\begin{tabular}{cc}
\hline Polymer & Relative etch rate \\
\hline Novolak & 1.00 \\
PVP & 1.07 \\
VP $_{50}-$ tBuA $_{50}$ & 1.33 \\
VP $_{79}-$ EAdMA $_{21}$ & 0.98 \\
VP $_{56}-$ EAdMA $_{44}$ & 0.96
\end{tabular}

Conditions: $\operatorname{Ar} 200 \mathrm{sccm}, \mathrm{C}_{4} \mathrm{~F}_{8} 10 \mathrm{sccm}, \mathrm{O}_{2} 20$ sccm, pressure $0.5 \mathrm{~Pa}, \mathrm{P} \mu 400 \mathrm{~W}$ 
sist using a magnetron plasma reactive ion etcher (Table 3). The etching conditions were $200 \mathrm{sccm}$ of $\mathrm{Ar}, 10 \mathrm{sccm}$ of $\mathrm{C}_{4} \mathrm{~F}_{8}$, and $20 \mathrm{sccm}$ of $\mathrm{O}_{2}$ at 0.5 $\mathrm{Pa}$ and the microwave power was $400 \mathrm{~W}$.

The tBu group containing resist has the highest etch rate because the substituent has an acyclic structure. The EAd group containing resist, however, had a slower etch rate compared with PVP. Note that the higher EAd unit concentration makes the dry etching rate decrease. As a result, the dry etching durability of poly $\left(\mathrm{VP}_{79}-\mathrm{EAdMA}_{21}\right)$ is about 1.3 times higher than that of poly $\left(\mathrm{VP}_{50^{-}}\right.$ $\mathrm{tBuA}_{50}$ ) and 1.1 times higher than that of PVP. Therefore, by using the resist, we can reduce a film thickness thirty percent in pattern fablication as compared with the poly $\left(\mathrm{VP}_{50}-\mathrm{tBuA}_{50}\right)$-based resist. We believe that the reduced thickness of the resist is favorable to obtain a higher sensitivity and higher resolution.

\section{Summary}

Vinylphenol-based resists containing acidcleavable adamantyl protective groups were prepared for use in chemically amplified EB resists. We found that the alicyclic groups have a strong dissolution inhibition, twice as large as that of the acyclic group, and therefore, they should give good lithographic performance when used as protective groups. 'H-NMR spectroscopy revealed that the reactivity of the EAd group is 3.4 times higher than that of the $\mathrm{tBu}$ group. We think that the inductive effect of the methyl group in ethyl substituent strongly stabilizes the carbonium ion of the intermediate, which contributes to the high reactivity of EAd group.

We also found that the dry etching durability of the resist is 1.3 times higher than that of the tBu containing resist. By using a poly $\left(\mathrm{VP}_{79}\right.$-EAd$M A_{21}$ )-based resist, we delineated 98-nm hole patterns as well as $120-\mathrm{nm} \mathrm{L} / \mathrm{S}$ patterns by EB exposures $(50 \mathrm{keV})$. Furthermore, the resist is applicable to 248 -nm lithography because it resolved 140-nm L/S patterns by 248-nm exposures. From the dry-etching durability perspective, we believe that the resist can be used at a reduced thickness, which contributes both resolution and sensitivity.
Further chemical and lithographic evaluations are currently in progress.

\section{Acknowledgments}

We thank A. Otoguro and S. Takechi (Fujitsu Ltd.) for their assistance with the 248-nm exposures.

\section{References}

1. S. D. Berger, J. M. Gibson, R. M. Camarda, R. C. Farrow, H. A. Huggins, J. S. Kraus, and J. A. Liddle, J. Vac. Sci. Technol., B9 (6), 2996 (1991).

2. H. C. Peiffer and W. Stickel, Microelectronic Engineering, 27, 143 (1995).

3. H. Yasuda, S. Arai, J. Kai, Y. Ooae, T Abe, S. Maruyama and T. Kikuchi, J. Vac. Sci. Technol., B14 (6), 3813 (1996).

4. N. Hayashi, S. M. A. Hesp, T. Ueno, M. Toriumi, and S. Nonogaki, Proc. ACS DIv. Polym. Mater. Sci. Eng., American Chemical Society, Miami Beach, FL, September 11-12, 61, 417-421 (1982); T. Niinomi, H. Tomiyasu, Y. Kameyama, M. Tsukamoto, Y. Tanaka, J. Fujita, S. Shimomura, and T. Ochiai, Proc. SPIE, 2724, 175 (1996)

5. H. Ito, C. G. Willson, and J. M. J. Frechet, Digest of Technical Papers of 1982 Symposium on VLSI Technology, 86-87 (1982).

6. H. Ito and M. Ueda, Macromolecules, 21, 1475 1482 (1988).

7. K. Nozaki, K. Watanabe, and E. Yano, Jpn. J. Appl. Phys., 35, Pt. 2, L 528-530 (1996); K. Nozaki, K. Watanabe, E. Yano, A. Kotachi, S. Takechi, and I. Hanyu, J. Photopolym. Sci. Technol., 9 (3), 509 (1996); S. Takechi, M. Takahashi, A. Kotachi, K. Nozaki, E. Yano, and I. Hanyu, J. Photopolym. Sci. Technol., 9 (3), 475 (1996).

8. G M. Wallraff, R. D. Allen, W. D. Hinsberg, C. F. Larson, R. D. Johnson, R. Dipietro, G. Breyta, N. Hacker, and R. R. Kunz, J. Vac. Sci. Technol., B11 (6), 2783-2788 (1993).

9. K. Nakano, K. Maeda, S. Iwasa, J. Yano, Y. Ogura, and E. Hasegawa, Proc. SPIE, 2195, 194 (1994).

10. J. Kon, K. Nozaki, T. Namiki, and E. Yano, Proc. SPIE 2000, to be published.

11. H. Ito, G. Breyta, D. Hofer, and R. Sooriyakumaran, J. Photopolym. Sci. Technol., 7 (3), 433 (1994).

12. S. Takechi, T. Kikukawa, Pat. Abstracts Jpn, No. 10182552 (Jul. 7, 1998). 